\title{
Research on the incentive of Government subsidy in the Innovation ecosystem of Guangzhou New Energy Automobile Industry
}

\author{
Xueyu Zhang ${ }^{1, a}$, Wenyong $\mathrm{Li}^{2}$,b \\ ${ }^{1}$ Huali College Guangdong University of Technology Guagzhou, China \\ ${ }^{2}$ Huali College Guangdong University of Technolog Guagzhou, China
}

\begin{abstract}
Led by made in China 2025 and the 13th five-year Plan of Guangdong Province, the development of strategic emerging industries in Guangdong Province needs to build an innovation ecosystem. In the development of industrial innovation, the management and development of enterprises are affected by policy environment, technological innovation, talent incentive and so on. The profit transformation ability, research and task development ability of core enterprises still need to be improved. On this basis, this paper takes Guangzhou as an example to investigate the current situation of incentive implementation of innovative industry and the role of industrial technological innovation from the starting point of government subsidy policy.Through the analysis of the different roles in each stage of the innovation process to achieve complementary advantages, the transformation of enterprise management mechanism, highlight the incentive mechanism of the innovation ecosystem, and achieve the healthy development of the industrial innovation ecosystem.
\end{abstract}

\section{Introduction}

In August 2017, the 13th five-year Plan for the Development of Strategic emerging Industries in Guangdong Province (hereinafter referred to as "the Plan") was formally issued and put forward, untill2020, the output value of the new generation of information technology industry in Guangdong Province will exceed 3 trillion yuan, forming three to four trillion yuan pillar industries, such as biology, high-end equipment manufacturing, green low carbon, and digital creativity. The added value of strategic emerging industries accounts for $16 \%$ of GDP, and the added value of high-tech manufacturing accounts for more than $30 \%$ of industries above scale.

From a full range of point of view, the development advantages of the three major industries are obvious. Among them, by the end of 2020, Guangdong has a production capacity of more than 20,000 new energy vehicles, accounting for $40 \%$ of the country's power battery production. From a sub-regional point of view, the Pearl River Delta is still in an absolutely dominant position in the development of strategic emerging industries in the province. In 2013, the added value of strategic emerging industries in the nine cities of the Pearl River Delta was about 270 billion yuan, accounting for about $90 \%$ of the total value of strategic emerging industries in the province, realizing profits of 855,22 billion yuan, with a proportion of $87.4 \%$, the value of export delivery accounted for more than $95 \%$. As of 2015 , nearly $71 \%$ of the technologies in Guangdong Province have been realized through independent innovation, gradually shortening the level difference with innovative countries or regions.

\section{Value Analysis of Industrial Innovation}

The promotion and application of new energy vehicles by the government is mainly based on the purpose of "promoting energy saving and emission reduction and promoting air pollution control". Guangzhou is the capital city of Guangdong, and it is also a pilot city for the demonstration and promotion of energy-saving and new energy vehicles. From the current research, there is little research on how to promote the development of strategic emerging industries in Guangdong Province, and less research on how to build a more complete service support system. This paper discusses the development needs and characteristics of strategic emerging industries in Guangdong Province, and finds out that the industrial service support system needs to be improved. The data of new energy vehicles in Guangzhou are used to empirically study the impact of science, technology, finance and other factors on the development of strategic emerging industries, which enriches the theoretical research at the present stage. The structure of the innovation ecosystem of the new energy automobile industry is shown in Figure 1 .

ae-mail: 546111699@qq.com be-mail: 747317364@qq.com 


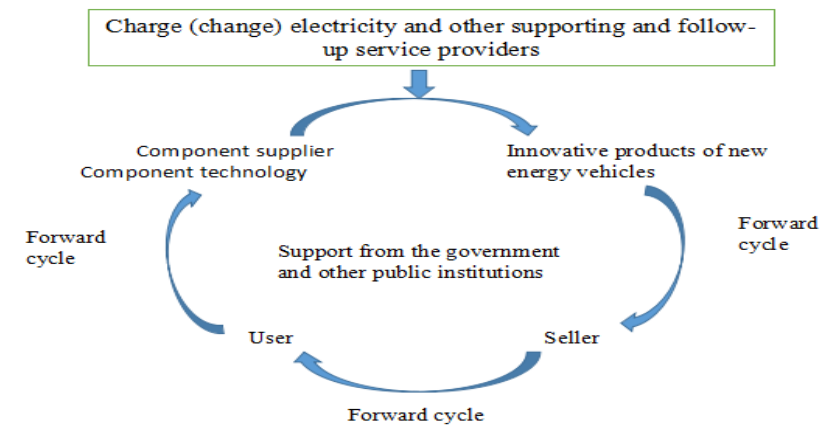

Fig1. Basic structure of innovative ecosystem of new energy vehicles

In practice, the main means of government support to strategic emerging industries is direct subsidies, in which new energy vehicles occupy the main position in this aspect, but due to the asymmetry of information and the adverse selection behavior of enterprises. Based on the development of strategic emerging industries in Guangdong Province, combined with empirical results, put forward relevant policy improvement measures, has a certain practical significance. It is of certain reference value to study the development status of new energy vehicles in Guangzhou and summarize and enhance the cooperation and competition of industrial technological innovation.

\section{Analysis on the present situation of Innovation and Popularization of New Energy Automobile Industry in Guangzhou}

Guangzhou has issued more than 17800 new energy vehicle license plates, more than 60, 000 new energy vehicles in the city, a cumulative charge of more than 300 million degrees, driving mileage of more than 2.1 billion kilometers, and remarkable results in energy saving and emission reduction. At the end of July 2018, about 20,000 charging facilities of various types were built in the city, and then the annual increment of charging facilities increased significantly. At the Guangzhou intelligent management meeting of charging facilities, 55 charging operators have been registered, 14500 charging piles are connected to the platform, and the annual charging capacity is 69 million kilowatt-hours, and an urban charging service network of a certain scale has been initially built. The promotion of new energy vehicles in Guangzhou is progressing step by step, first in the field of public transport, then in the field of official vehicles, and then in the field of private cars, which is expected to reach 200000 by $2020 .^{[1]}$

\subsection{New energy rental car}

Guangzhou leasing electric vehicle mode is flexible, and new energy vehicle leasing started early. Guangzhou Xiangxiang is the founder of the earliest green leasing model and cooperates with charging pile operators in Guangzhou to arrange vehicle rental sites in qualified areas of Guangzhou. It is convenient for users to borrow and return vehicles. Ring out car rental put forward "time- sharing rental", "customized rental", "private car sharing" three rental models, in view of the particularity of the work of different customer groups, set up a holiday discount package. Guangzhou also encourages individuals to buy new energy vehicles to participate in the car rental business for "private car sharing" car owners can also make personalized settings for users.

\subsection{Guangzhou taxi field}

Guangzhou has made great efforts to invest in the field of new energy taxis, actively introducing relevant policies to promote the promotion and application of new energy policies, and the people's government has also clearly defined the promotion of new energy taxis, investing in about 2000 new energy taxis, while promoting the sale of new energy vehicles, enhance urban energy conservation and environmental protection. The government policy proposes that the proportion of pure electric vehicles should not be less than $80 \%$ of the new or newly added parade taxis in Guangzhou from 2018, and the proportion of pure electric vehicles should be increased by 5 percentage points year by year, and the rest will use new energy vehicles. By the end of 2022, cruise taxis in Guangzhou will basically achieve comprehensive new energy.

At present, Guangzhou encourages new or updated taxis to use new energy vehicles through the arrangement of capacity indicators, encourages the establishment of professional new energy taxi operation companies, supports the active exploration of innovative business models, and strives to achieve a win-win situation for all parties in operation. Supporting the construction of infrastructure by means of "decentralized slow charging mainly, fast charging as a supplement, and network layout".

\subsection{Bus field}

Guangzhou Dingli promotes the electrification of buses, takes the lead in the promotion and application of public services, encourages sanitation and logistics to give priority to the use of new energy vehicles. At the same time, supports the use of new energy vehicles for official vehicles. Guangzhou has 11,160 energy-saving and new energy buses, accounting for about 75 percent of the total, of which 3,767 are pure electric buses. Party and government organs, public institutions, and state-owned enterprises vigorously promote the demonstration and application of new energy vehicles, and support the inclusion of GAC GE3 and other independent brands of pure electric vehicles in the scope of party and government organs, enterprises and institutions, such as confidential communications and emergency response, so as to highlight the centralized demonstration effect. ${ }^{[2]}$ We will organize various districts to carry out the construction of charging facilities in 100 public parking lots, and promote the construction of about 8,000 charging facilities in more than 100 existing large-scale shopping malls, cultural and sports venues, convention and exhibition centers, transportation hubs and other public parking lots. 


\section{Investigation and Model Analysis of Innovation ecosystem subsidy in Guangzhou New Energy Automobile Industry}

The Guangzhou government takes the lead in building a network of supporting infrastructure for new energy taxis, which provides infrastructure as a guarantee for the use of new energy taxis. The government encourages the society to set up professional operation companies for new energy taxis to support the active exploration of innovative business models and the rapid development of new energy taxis. Guangzhou BAIC New Energy provides technical support to solve the problem of difficult charging, and takes the lead in delivering power-changing taxis for Guangzhou to be put into use, which solves the problem of inconvenient charging of taxis on the way.

The research team visited some districts of Guangzhou and conducted one-on-one interviews with local automobile industry experts, new energy vehicle dealers, sales consultants, car owners, taxi drivers and ordinary citizens, as shown in Table 1. The research team collect relevant data in the field of promotion and use of new energy vehicles.

Table1. Research outline of New Energy vehicles

\begin{tabular}{|c|c|c|c|}
\hline ОJЕСТ & \multicolumn{2}{|c|}{ Sales field } & FIELD OF USE \\
\hline \multirow{2}{*}{$\begin{array}{c}\text { THE } \\
\text { MARKETING } \\
\text { SITUATION OF } \\
\text { ELECTRIC } \\
\text { VEHICLES ON } \\
\text { SALE IN } \\
\text { GUANGZHOU }\end{array}$} & $\begin{array}{l}\text { Government fiscal and } \\
\text { tax subsidy policy }\end{array}$ & Purchase tax & $\begin{array}{l}\text { Supporting } \\
\text { facilities }\end{array}$ \\
\hline & $\begin{array}{l}\text { Compulsory insurance, } \\
\text { vehicle and vessel tax, } \\
\text { commercial insurance }\end{array}$ & $\begin{array}{l}\text { Merchant sales } \\
\text { strategy and plan }\end{array}$ & $\begin{array}{c}\text { The use of New } \\
\text { Energy vehicles } \\
\text { in Urban Public } \\
\text { Transport }\end{array}$ \\
\hline OTHER & $\begin{array}{ll}\text { Sales stores and } \\
\text { distribution of new } \\
\text { energy vehicles }\end{array}$ & $\begin{array}{l}\text { Do customers from } \\
\text { other places enjoy the } \\
\text { subsidy policy when } \\
\text { purchasing new energy } \\
\text { vehicles in Guangzhou }\end{array}$ & $\begin{array}{c}\text { The situation of } \\
\text { sharing cars and } \\
\text { online car- } \\
\text { hailing. }\end{array}$ \\
\hline
\end{tabular}

4.1 The new energy automobile industry in Guangzhou has entered a period of growth.

Guangzhou new energy vehicles have been gradually promoted in the field of public transport, official vehicles, logistics vehicles and so on. The development of new energy vehicles in Guangzhou is in line with the ecosystem of environment and resources. Under the market conditions of the prosperous purchase and sale of traditional fuel vehicles, it is impossible to realize the benign and rapid development of the new energy vehicle industry simply by relying on the spontaneous regulation of the market. At this time, the government's macrocontrol, especially the "subsidy" policy, must play a leading role.Due to the enhancement of the efficiency of technological innovation activities, the technological achievements developed by innovative enterprises investing a lot of resources can benefit all kinds of subjects in the innovation ecosystem without paying a price, thus greatly reducing the $\mathrm{R} \& \mathrm{D}$ cost of collaborative innovation enterprises and greatly improvingIn the promotion of new energy vehicles in Guangzhou. The government encourages basic innovation in a variety of ways, reduces research and development costs, promotes the new energy vehicle industry, and makes it enter a period of rapid growth. the innovation benefits of the whole innovation ecosystem.

\subsection{Government subsidies focus on ecosystem balance}

The notice on the Financial support Policy for the Promotion and Application of New Energy vehicles from 2016 to 2020 clearly points out that the subsidy for new energy vehicles will gradually adopt the withdrawal mechanism. ${ }^{[3]} \mathrm{As}$ an important means for the state to support the development of the new energy vehicle industry, government subsidies need to consider the most effective way to subsidize the industry based on the effectiveness of the innovation ecosystem of the industry. In the long-term dynamic evolution process of industrial innovation, adaptation and other processes form a dynamic equilibrium relationship, which is mainly manifested in the cooperation and competition among populations.

\section{Empirical analysis}

\subsection{Model hypothesis}

In order to study the problem conveniently, we select the new energy vehicle ecosystem in the high niche enterprise $\mathrm{M}$ as the representative of the whole vehicle enterprise, and select the parts manufacturing enterprise $\mathrm{S}$ with low niche. The early rise of the new energy vehicle ecosystem can still see parts and components enterprises marching into the field of vehicle production, mainly due to the parts enterprises' mastery of key technologies. In the long-term development and adaptation, the niche may be reversed. At this time, the cooperation and competition among ecological enterprises is the norm, and government subsidies act as the key resources, which will have a great impact on the ecosystem. We assume that the information between the government and the enterprise is complete, that is, the enterprise sees the government's subsidy policy and chooses the optimal innovation input, and we use the Cobb-Douglas production function to reflect the output of the enterprise innovation input.

$\mathrm{Q}=\mathrm{AX} \mathrm{X}^{\mathrm{a}} \mathrm{Y}^{\mathrm{B}}$

$\mathrm{Q}$ is the output, $\mathrm{X}$ and $\mathrm{Y}$ are the innovation inputs of $\mathrm{M}$ and $\mathrm{S}$ enterprises.

Then $X>0, Y>0$,TIX A brings result output coefficient for innovation input, $\alpha$ and $\beta$ are the influence factors of innovation input on achievement output, $0<\alpha, \quad \beta<1$, and $\alpha+\beta<1$.

The profit functions of $\mathrm{M}$ and $\mathrm{S}$ enterprises are respectively:

$\pi_{\mathrm{M}}=\rho_{\mathrm{M}} \mathrm{Q}-\mathrm{X}+\delta_{\mathrm{M}} \mathrm{X}$
$\pi_{\mathrm{s}}=\rho_{\mathrm{s}} \mathrm{Q}-\mathrm{X}+\delta_{\mathrm{s}} \mathrm{X}$

$\delta_{\mathrm{M}}$ and $\delta_{\mathrm{s}}$ are the subsidy coefficients of the government's innovation input to $M$ enterprises and $S$ 
enterprises, $\rho_{M}$, and $\rho_{s}$ are the marginal benefits of $M$ enterprises and $\mathrm{S}$ enterprises, $\delta_{\mathrm{M}}, \rho_{\mathrm{M}}$, and $\rho_{\mathrm{s}}$ are all constants greater than 0 .

Solve the problem of insufficient investment in enterprise innovation in the innovation ecosystem and the effectiveness of the government. The function can be defined as the sum of the profits of two enterprises minus government subsidies, (2) adds (3) and subtracts government subsidies to get the following expression:

$\mathrm{U}_{\mathrm{G}}=\left(\rho_{\mathrm{M}}+\rho_{\mathrm{s}}\right) \mathrm{Q}-\mathrm{X}-\mathrm{Y}$

$\mathrm{U}_{\mathrm{G}}$ is the utility function of the government.

\subsection{Subsidy Policy under Cooperative equilibrium and competitive equilibrium}

Below, we will analyze the subsidy under the equilibrium of cooperation and competition respectively.

Cooperation equilibrium the two enterprises reach a cooperation agreement in order to maximize their interests. At this time, the total profit function of the two enterprises is:

$\operatorname{Maxrr}=\left(\rho_{M}+\rho_{\mathrm{s}}\right) \mathrm{Q}-\mathrm{X} \quad\left(1-\rho_{\mathrm{M}}\right)-\mathrm{Y} \quad\left(1-\rho_{\mathrm{s}}\right)$

By calculating the partial derivatives of $\mathrm{X}$ and $\mathrm{Y}$ and making them equal to 0 , we can obtain:

$$
\begin{aligned}
& X=\left[A\left(\rho_{M}+\rho_{S}\right)\right]^{\frac{1}{1-\alpha-\beta}}\left[\frac{\alpha}{1-\delta_{M}}\right]^{\frac{1-\beta}{1-\alpha-\beta}}\left[\frac{\beta}{1-\delta_{S}}\right]^{\frac{\beta}{1-\alpha-\beta}} \\
& Y=\left[A\left(\rho_{M}+\rho_{S}\right)\right]^{\frac{1}{1-\alpha-\beta}}\left[\frac{\alpha}{1-\delta_{M}}\right]^{\frac{\alpha}{1-\alpha-\beta}}\left[\frac{\beta}{1-\delta_{S}}\right]^{\frac{1-\alpha}{1-\alpha-\beta}}
\end{aligned}
$$

Replace (6) and (7) into(4), and find $\delta_{M}$ and $\delta_{s}$. And make it and so on. At 0 , the optimal subsidy for the government is:

$$
\delta_{M}^{*}=\delta_{S}^{*}=0
$$

In the innovation ecosystem of the new energy automobile industry, under the competitive equilibrium, $\mathrm{M}$ is the high position and $\mathrm{S}$ is the low position to follow. Its characteristic is that the government determines the subsidy, M changes with the subsidy innovation, and $\mathrm{S}$ determines the innovation investment with M. Moreover, at present, the total economic output of Guangzhou, Shenzhen and Hong Kong is very close to each other, forming the unique multi-engine characteristics of Guangdong-Hong Kong-Macau Greater Bay Area.

Given the government subsidy and $\mathrm{S}$ enterprise innovation investment, $\mathrm{M}$ enterprise makes the innovation investment of profit maximization, so that the first order partial derivative of (3) is equal to 0 .

$$
Y=\left[\frac{1-\delta_{S}}{\beta \rho_{S} A}\right]^{\frac{1}{\beta-1}} X^{\frac{-\alpha}{\beta-1}}
$$

$\mathrm{M}$ enterprise maximizes its own according to the response function of $\mathrm{S}$ enterprise.Profit function, put the (9) into (2), and make its first partial derivative equal to 0.

$$
\begin{aligned}
& X=A^{\frac{1}{1-\alpha-\beta}}(1-\beta)^{\frac{\beta-1}{1-\alpha-\beta}}\left(\frac{\alpha \rho_{M}}{1-\delta_{M}}\right)^{\frac{1-\beta}{1-\rho_{S}}}\left(\frac{\beta \rho_{S}}{1-\rho_{S}}\right)^{\frac{\beta}{1-\alpha-\beta}} \\
& Y=A^{\frac{1}{1-\alpha-\beta}}(1-\beta)^{\frac{-\alpha}{1-\alpha-\beta}}\left(\frac{\alpha \rho_{M}}{1-\delta_{M}}\right)^{\frac{\alpha}{1-\rho_{S}}}\left(\frac{\beta \rho_{S}}{1-\rho_{S}}\right)^{\frac{1-\alpha}{1-\alpha-\beta}}
\end{aligned}
$$

The government determines the optimal subsidy, putting (10) and (11) for generation. $\delta \mathrm{M}$ and $\delta \mathrm{s}$, respectively. And make it equal to 0 , we can obtain:

$$
\begin{aligned}
& \delta_{M}^{1}=1-\frac{\rho_{M}}{(1-\beta)\left(\rho_{M}+\rho_{S}\right)} \\
& \delta_{S}^{1}=\frac{\rho_{S}}{\left(\rho_{M}+\rho_{S}\right)}
\end{aligned}
$$

As can be seen from equation (13), $\rho_{\mathrm{M}}$, and $\rho_{\mathrm{s}}$ are constants greater than zero, so $\delta_{S}^{1}>0$.The government should subsidize the enterprises in the stock of spare parts.

$$
\frac{\rho_{M}}{\rho_{S}} \leq \frac{1-\beta}{\beta}, \delta_{M}^{1} \geq 0 \text {, The government should }
$$
subsidize $\mathrm{M}$ enterprises.

$$
\frac{\rho_{M}}{\rho_{S}} \geq \frac{1-\beta}{\beta}, \delta_{M}^{1} \leq \mathrm{O}, \text { The government should tax }
$$

$\mathrm{M}$ enterprises. That is to say, $\mathrm{M}$ enterprise already has a very high marginal income. Tax should be levied to restrain enterprises' excessive investment in innovation.

\subsection{Comparison and analysis}

The government should take a variety of measures to encourage cooperation among various groups within the innovation ecosystem and save government subsidy resources. Within the innovation ecosystem, it is possible to achieve full innovation cooperation between and within populations. With the continuous increase of innovation investment, it is possible for government subsidies to withdraw completely. It can be seen that the withdrawal of government subsidies is not a matter of time, but must form such an innovative environment of active innovation and cooperative innovation within the innovation ecosystem.

\section{Conclusion}

The government should shift the focus of subsidies to the populations of parts and components with weak niche, raw materials, and so on, so as to improve the ability of basic innovation. Only in this way can we fundamentally enhance the new energy vehicle industry and enhance the international competitiveness of the new energy vehicle industry.Under the role of socialized benign coordination mechanism, government subsidies and incentives enhance the core competitiveness of the innovation ecosystem of the new energy automobile industry.

\section{Acknowledgment}

This research was financially supported by the Key Research Platforms and Scientific Research Projects of Guangdong Province in 2018 (Young Innovative Talents) "Research on Incentive Mechanism of Innovation Ecosystem Based on Guangzhou New Energy Automobile Industry " (Grant NO.2018WQNCX257).and the Key Research Platforms and Scientific Research Projects of Guangdong Province in 2018 (Young Innovative Talents) "Based on the Openness of Service Industry and Service Trade Innovation in the Pearl River Delta of Dawan District, Guangdong, Hong Kong and Macao"(Grant NO. 2018WQNCX261) 


\section{References}

1. Ruiqi Luo, Carding of the Promotion Policy of China's New Energy Automobile Industry, 2018(12):4.

2. Yanqing Guo, Research on subsidy in Innovation ecosystem of China's New Energy Automobile Industry, 2016(02).

3. Liping $\mathrm{Wu}$, Comparative Analysis of Market investigation on "Marketing Mode" of New Energy vehicles in Liuzhou and Guangzhou, 2020(01): 71-76.

4. Hao Pan, Collaborative Innovation Development Mode and Operation Mechanism of New Energy Automobile Industry in Shenzhen.Explore, Chinese business theory2018(29): 244-2 